\title{
Drifting postlarva of Callipallene brevirostris (Johnston, 1837) (Pycnogonida: Callipallenidae) from Roscoff (France)
}

\author{
Tobias Lehmann ${ }^{1}$ (D) Timea P. Neusser ${ }^{2} \cdot$ Katharina M. Jörger ${ }^{2} \cdot$ Roland R. Melzer $^{1,2}$
}

Received: 27 January 2021 / Revised: 10 March 2021 / Accepted: 12 March 2021 / Published online: 27 March 2021

(C) The Author(s) 2021
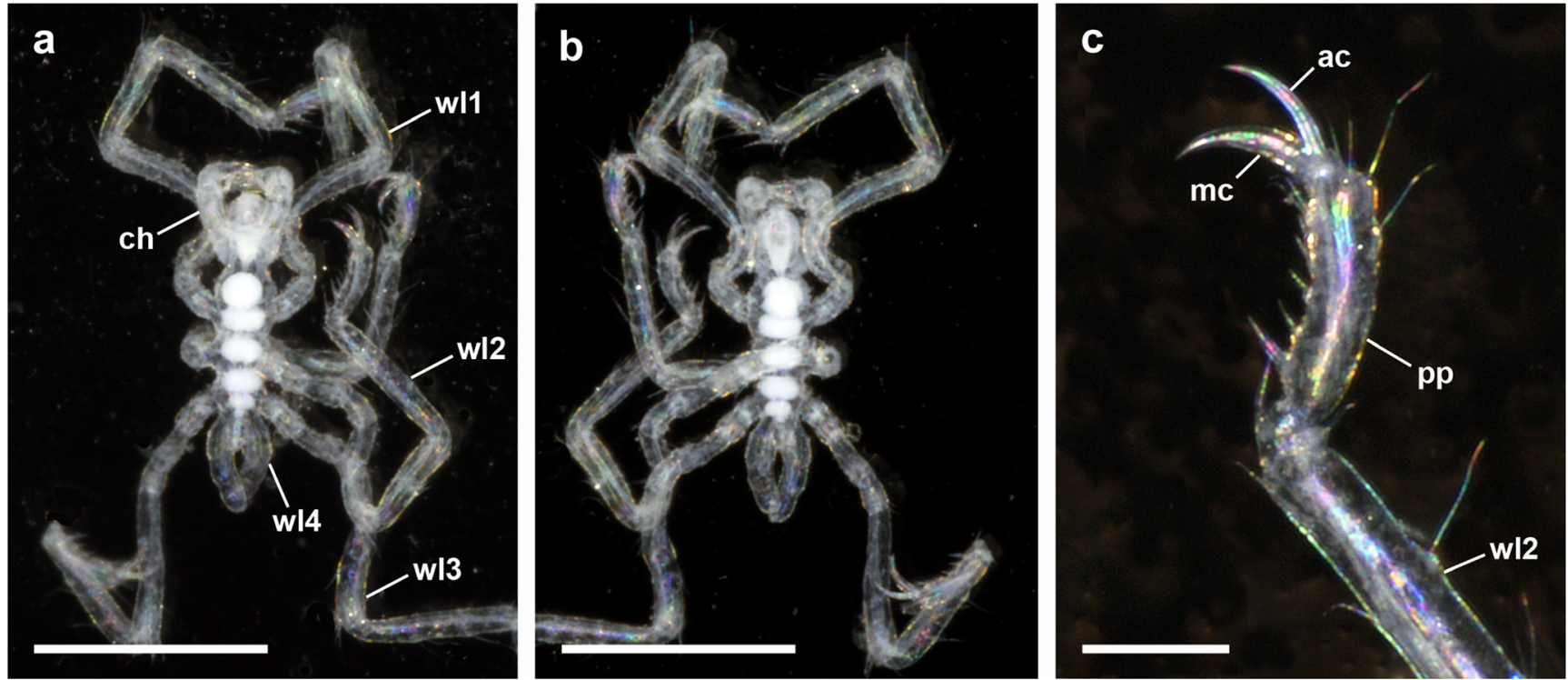

Fig. 1 Drifting postlarva of Callipallene brevirostris (Johnston, 1837) found in a plankton sample. a Dorsal view, bar $500 \mu \mathrm{m}$; b Ventral view, bar $500 \mu \mathrm{m}$; c Propodus of second walking leg with auxiliary claws more than two-thirds as long as the main claw, bar $100 \mu \mathrm{m}$. ac, auxiliary claw; ch, cheliphore; mc, main claw; pp, propodus; wl1-4, walking leg 1-4.

Communicated by L. Menzel

$\triangle$ Tobias Lehmann

lehmann@snsb.de

1 SNSB - Bavarian State Collection of Zoology, Münchhausenstraße 21, 81247 Munich, Germany

2 Department Biologie II, Ludwig-Maximilians-Universität München, Großhaderner Straße 2, 82152 Planegg-Martinsried, Germany 
Pycnogonids or sea spiders are exclusively marine invertebrates occurring from the littoral zone to the deep sea and are commonly found in benthic habitats. The complex and time-consuming brood care behaviour of the males results in a benthic lifestyle also of the protonymphon larvae, which is the most common pycnogonid hatching stage, and older larval or juvenile stages. Hence, most pycnogonids are benthic throughout their entire life - in contrast to many other marine arthropods, which have a pelagobenthic lifecycle. It is therefore generally assumed that the dispersal capacity of pycnogonids is relatively low, and, accordingly, the tendency towards allopatric speciation is strong compared to pelago-benthic forms. However, occasionally sea spiders are observed swimming in coastal surface waters (e.g. Ammothea magniceps Thompson, 1883, see Clark and Carpenter (1977)). Furthermore, some species are associated with pelagic gelatinous zooplankton such as scyphomedusae or doliolids (e.g. Bathypallenopsis tritonis (Hoek, 1883) upon Pandea rubra Bigelow, 1913, see Pagès et al. (2007)). Finally, very few records are from plankton samples (e.g. Propallene longiceps (Böhm, 1879), see Utinomi (1959) or protonymphon of Phoxichilidium femoratum (Rathke, 1799), see Malakhov and Bogomolova (2001)).

In June 2017, we found a sea spider postlarva in a typical plankton sample collected in the waters near Roscoff (France) using a standard planktonic net. The specimen could be determined as a postlarva of Callipallene brevirostris (Johnston, 1837) (specimen stored in ethanol in the Arthropoda varia section of the SNSB-Bavarian State Collection of Zoology as ZSMA 20190051). The cheliphores and the first three pairs of walking legs are developed. The fourth pair of walking legs is visible as limb buds, and the ovigerous legs are still absent (Fig. 1). The combination of the short neck and extremely long auxiliary claws is typical for C. brevirostris (Fig. 1). According to Morgan (1891), the postlarva of C. brevirostris leaves the male's ovigers at this advanced developmental stage. Although this finding is a single observation, we regard it as noteworthy, because this is one of the few records of pycnogonids found in a plankton sample. This rare finding indicates that at least for this species, a drift over greater distances can occur and the dispersal capacity might be higher than generally thought to be the case. In the case of the herein presented drifting Callipallene postlarva, we assume that we observed the effect of a rare drift accident rather than a regular element of this pycnogonid's lifecycle.

Acknowledgements We are grateful to the Station Biologique de Roscoff, France, for their excellent research facilities and especially to our captain Gilles Maron for providing the plankton sample. B.Sc. Lisa Niedermeier and Moritz Hackbarth are thanked for assistance in sorting and documentation. We also thank five anonymous reviewers for their comments.

Funding Open Access funding enabled and organized by Projekt DEAL.

\section{Declarations}

Conflict of interest The authors declare no competing interests.

Ethical approval This study complies with ethical standards, according to the rules and guidelines of the journal.

Sampling and field studies All necessary permits for fieldworks have been obtained from the competent authorities.

Data availability The data that support the findings of this study are available from the corresponding author upon reasonable request.

Author contribution TPM and KMJ conducted the fieldworks and sampling. TL wrote the manuscript with contributions of RRM. All the authors read and approved the final manuscript.

Open Access This article is licensed under a Creative Commons Attribution 4.0 International License, which permits use, sharing, adaptation, distribution and reproduction in any medium or format, as long as you give appropriate credit to the original author(s) and the source, provide a link to the Creative Commons licence, and indicate if changes were made. The images or other third party material in this article are included in the article's Creative Commons licence, unless indicated otherwise in a credit line to the material. If material is not included in the article's Creative Commons licence and your intended use is not permitted by statutory regulation or exceeds the permitted use, you will need to obtain permission directly from the copyright holder. To view a copy of this licence, visit http://creativecommons.org/licenses/by/4.0/.

\section{References}

Clark W, Carpenter A (1977) Swimming behaviour in a pycnogonid (note). N Z J Mar Freshwater Res 11:613-615

Malakhov V, Bogomolova E (2001) The first finding of a sea spider (Pantopoda) planktonic larva. Dokl Biol Sci 376:91-92

Morgan TH (1891) A contribution to the embryology and phylogeny of the pycnogonids. In: Studies from the Biological Laboratory of the John Hopkins University Baltimore, Vol 5, pp 1-76

Pagès F, Corbera J, Lindsay D (2007) Piggybacking pycnogonids and parasitic narcomedusae on Pandea rubra (Anthomedusae, Pandeidae). Plankt Benthos Res 2:83-90

Utinomi H (1959) Pycnogonida of Sagami Bay. Publ Seto Mar Biol Lab $7: 197-222$

Publisher's Note Springer Nature remains neutral with regard to jurisdictional claims in published maps and institutional affiliations. 